\title{
Perspective
}

PERSPECTIVE Actualité en histoire de l'art

Comptes rendus | 2010

\section{Hendrik Ziegler, Der Sonnenkönig und seine Feinde die Bildpropaganda Ludwigs XIV. in der Kritik, Petersberg, Michael Imhof Verlag, 2010}

\section{Raphaël Rosenberg}

\section{OpenEdition}

\section{Journals}

Édition électronique

URL : http://journals.openedition.org/perspective/2605

DOI : 10.4000/perspective.2605

ISSN : 2269-7721

Éditeur

Institut national d'histoire de l'art

Référence électronique

Raphaël Rosenberg, «Hendrik Ziegler, Der Sonnenkönig und seine Feinde die Bildpropaganda Ludwigs XIV. in der Kritik, Petersberg, Michael Imhof Verlag, 2010 », Perspective [En ligne], Comptes rendus, mis en ligne le 04 septembre 2013, consulté le 01 octobre 2020. URL : http://journals.openedition.org/ perspective/2605; DOI : https://doi.org/10.4000/perspective.2605 
Hendrik Ziegler, Der Sonnenkönig und seine Feinde die Bildpropaganda Ludwigs XIV. in der Kritik, Petersberg, Michael Imhof Verlag, 2010

Raphaël Rosenberg

\section{RÉFÉRENCE}

Hendrik Ziegler, Der Sonnenkönig und seine Feinde die Bildpropaganda Ludwigs XIV. in der Kritik, Petersberg, Michael Imhof Verlag, 2010. 
1 Depuis le livre de Peter Burke (The Fabrication of Louis XIV, 1992), nous savons que la politique des images du Roi Soleil dépasse de loin celle de ses prédécesseurs. Hendrik Ziegler élargit ce sujet en étudiant le contexte international de cette politique. Il reconstruit minutieusement et à l'aide de sources partiellement inédites une vraie guerre des images que se livrèrent la France de Louis XIV et les puissances étrangères, la Hollande et surtout l'empire des Habsbourg. Les trois chapitres se concentrent sur l'évolution de l'iconographie solaire, sur les monuments de Louis XIV (Place des Victoires, Place Vendôme, Villa Médicis) et sur la voûte de la Grande Galerie de Versailles. Comme les ouvrages plus

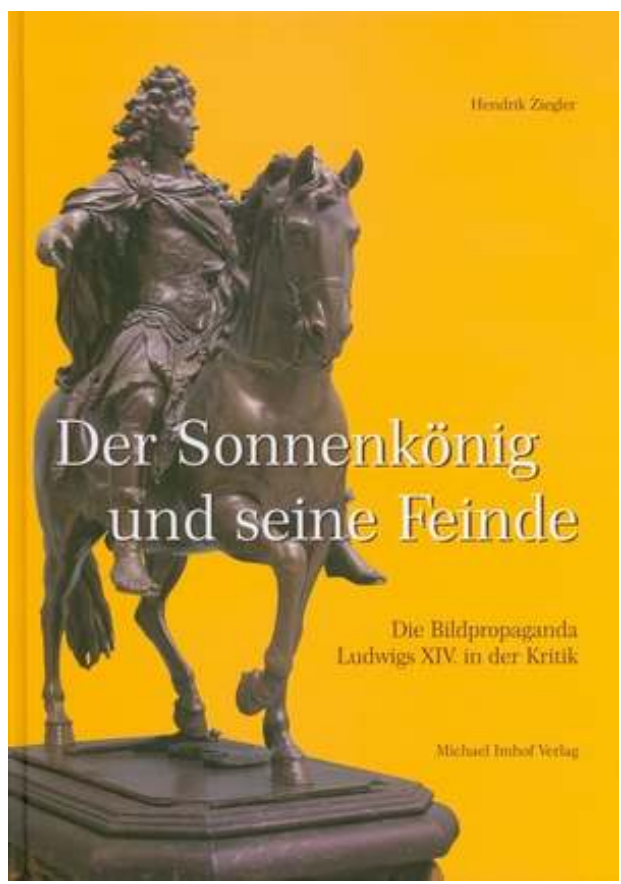
spécifiques de Quaeitzsch et de Schneider (voir ci-dessus) et bien que les trois auteurs, dont la perspective et la méthodologie diffèrent, semblent ne pas avoir eu connaissance mutuelle de leurs recherches, Ziegler aussi explique comment la représentation du monarque a dû profondément évoluer au cours de son règne. 